\title{
Axonemal Dynein Arms
}

\author{
Stephen M. King \\ Department of Molecular Biology and Biophysics, University of Connecticut Health Center, \\ Farmington, Connecticut 06030-3305 \\ Correspondence: king@uchc.edu
}

Axonemal dyneins form the inner and outer rows of arms associated with the doublet microtubules of motile cilia. These enzymes convert the chemical energy released from adenosine triphosphate (ATP) hydrolysis into mechanical work by causing the doublets to slide with respect to each other. Dyneins form two major groups based on the number of heavychain motors within each complex. In addition, these enzymes contain other components that are required for assembly of the complete particles and/or for the regulation of motor function in response to phosphorylations status, ligands such as $\mathrm{Ca}^{2+}$, changes in cellular redox state and which also apparently monitor and respond to the mechanical state or curvature in which any given motor finds itself. It is this latter property, which is thought to result in waves of motor function propagating along the axoneme length. Here, I briefly describe our current understanding of axonemal dynein structure, assembly, and organization.

M otile cilia ${ }^{1}$ are organelles involved in the transport of fluids (such as mucus flow in the lungs) and in the directed movement of individual cells (e.g., sperm). Reactivation of demembranated organelles has clearly shown that all the components necessary to generate and propagate waveforms are built into the microtubular axoneme, which can thus be considered a solid-state (or hard-wired) motility system requiring only an external energy source to function. Indeed, in vitro, these structures even retain the ability to alter their waveform or beat frequency in response to alterations in added signaling factors. Although the path by which signals are propagated through the axonemal

${ }^{1}$ In some organisms, such as Chlamydomonas, this organelle is commonly referred to as a flagellum. However, here I use the term cilium throughout for clarity. superstructure is complex, ultimately the motile behavior is generated by two rows of dynein arms that are permanently attached to the Atubule of one microtubule doublet and transiently interact in an adenosine triphosphate (ATP)-dependent manner with the B-tubule of an adjacent doublet. This generates a sliding force that is converted to bending by additional structures (including the nexin-dynein regulatory complex) that link the doublets circumferentially. In this article, I briefly describe the basic composition of these dynein complexes and how they are preassembled in cytoplasm and trafficked into the ciliary shaft. I also discuss how they are incorporated into the axoneme, their patterning within the superstructure, the mechanisms by which they are regulated to generate specific ciliary beat patterns, and the general consequences of their dysfunction in mammals.

Editors: Wallace Marshall and Renata Basto

Additional Perspectives on Cilia available at www.cshperspectives.org

Copyright (C) 2016 Cold Spring Harbor Laboratory Press; all rights reserved; doi: 10.1101/cshperspect.a028100 Cite this article as Cold Spring Harb Perspect Biol 2016;8:a028100 
S.M. King

As dyneins are highly complex macromolecular systems containing, in some cases, $>20$ different protein components, and as they have been studied over many years in numerous different model systems, their nomenclature has become extraordinarily complex and highly confusing. Here, I use the nomenclature scheme used in Chlamydomonas; to translate this to orthologous components in other organisms, the reader is referred to Hom et al. (2011), which presents a comprehensive taxonomic guide to axonemal dynein nomenclature.

\section{COMPOSITION OF DYNEIN ARMS}

The dynein arms that power ciliary motility may be classified into two distinct groups based on the number of heavy-chain motor units that they contain. These motors are $\sim 4500$ residues and consist of an amino-terminal region required for assembly, followed by a motor unit consisting of a hexameric ring of nonidentical $\mathrm{AAA}^{+}$domains (Fig. 1A,B). The microtubulebinding region is located at the tip of a coiled coil that emanates from AAA4 and also interacts with a second coiled-coil segment (termed the buttress) that derives from AAA5. Finally, there is a carboxy-terminal domain that associates across the plane of the AAA ring and may be involved in regulating motor activity.

The first dynein class consists of single motors that are associated with a molecule of actin and either a specific light chain (termed p28 in Chlamydomonas; dyneins a, c, and d) or the $\mathrm{Ca}^{2+}$-binding protein centrin (dyneins b, e, and $\mathrm{g}$ ); dynein $\mathrm{d}$ also has two additional components p38 and p44. These motors form a subset of the inner dynein arms and are arrayed in a complex manner both along the axonemal length and potentially even on distinct outer doublets. In addition to this major group of monomeric dyneins, there are also several "minor" dyneins that are present in greatly reduced quantity (Yagi et al. 2009). In Chlamydomonas, one of these (termed DHC3) is estimated to be almost $100 \mathrm{kDa}$ larger than other dyneins because of a series of insertions within the $\mathrm{AAA}^{+}$ ring domain. Although little is known about the composition or role of these minor isoforms, their discrete localization in the region of the axoneme near the ciliary base supports the idea that they may be involved in bend initiation. Chlamydomonas mutants defective for actin are actually viable and the lack of this protein leads to the failure of most of these monomeric heavy-chain dyneins to assemble (Kato-Minoura et al. 1997). However, it has been observed that two particular motors are still incorporated into the axonemal superstructure as they are able to use an actin-related protein that becomes up-regulated in the mutant strain (Kato-Minoura et al. 1998). The p28 light chain is also absolutely required for the assembly of those dyneins with which it associates (LeDizet and Piperno 1995).

The second dynein class includes both the outer arm (Fig. 1C) and an additional inner arm termed I1 or $\mathrm{f}$ (see Table 1). These motors are built in a manner related to that of canonical cytoplasmic dynein and the dynein that powers retrograde intraflagellar transport (IFT). In all of these complexes, two heavy-chain motors (or three in the case of outer arms in organisms such as Chlamydomonas and Tetrahymena) associate together via their amino-terminal regions. Cytoplasmic and IFT dyneins are formed from homodimers of heavy chains. However, for axonemal dyneins these multimotor enzymes contain nonidentical heavy chains encoded by different genes that show distinct motor and ATPase properties; indeed, the individual motor units within the same complex are even regulated by different signaling inputs. The heavy-chain amino-terminal segments also bind an additional subcomplex consisting of two WD-repeat intermediate chains and light chains belonging to three conserved classes (namely, DYNLL1/2 or LC8, DYNLT1 or Tctex1, and DYNLRB1/2, roadblock, or LC7) (King and Patel-King 1995b; Harrison et al. 1998; Bowman et al. 1999). This subcomplex is absolutely required for motor integrity and assembly and, for example, mutants defective for the outer arm WD-repeat intermediate chains are completely unable to assemble these structures into the axoneme (Mitchell and Kang 1991; Wilkerson et al. 1995). The outer arms from metazoans also contain an additional in- 


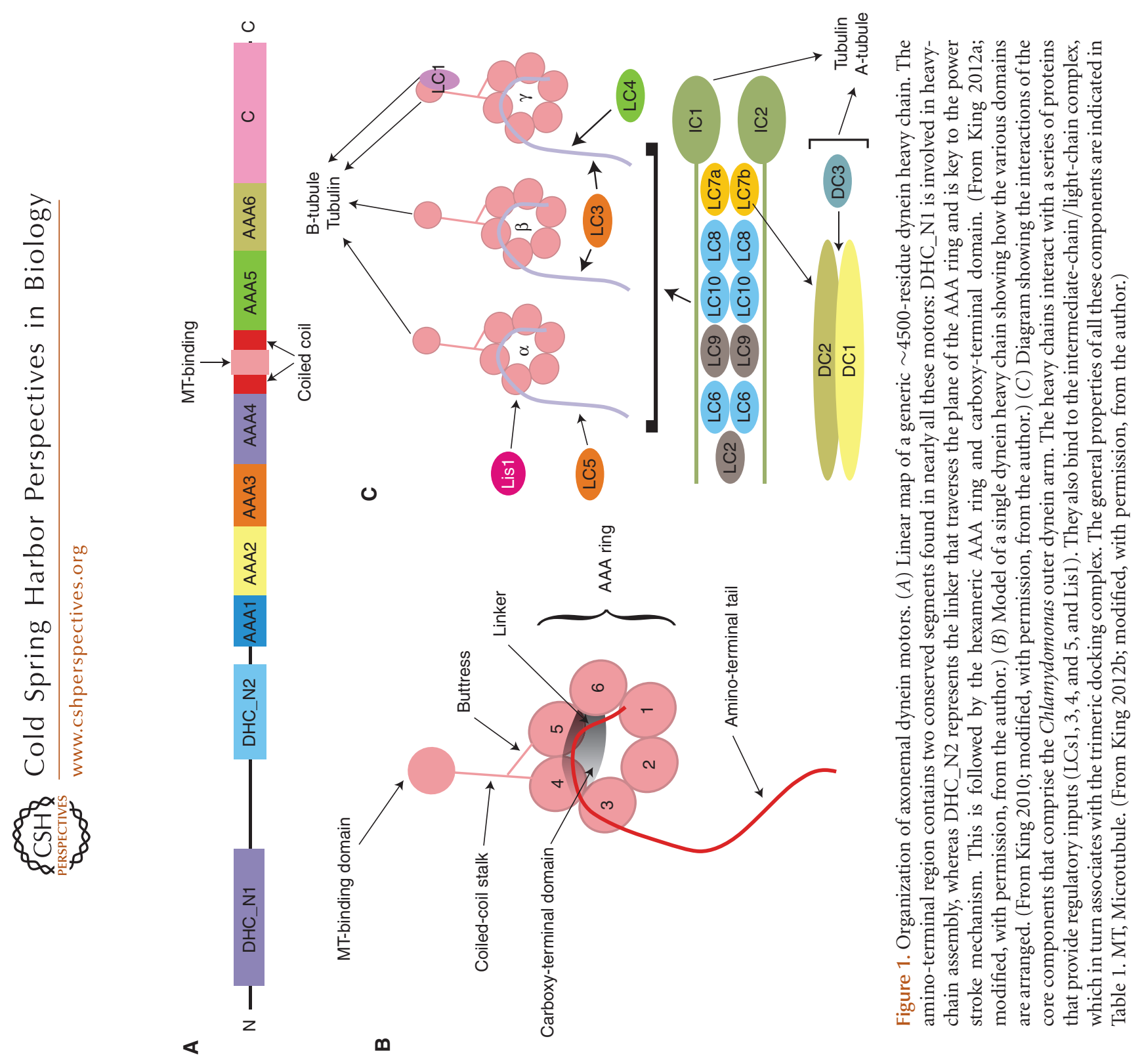


S.M. King

termediate chain that consists of an amino-terminal thioredoxin module followed by two or three nucleoside diphosphate kinase catalytic cores (Ogawa et al. 1996; Padma et al. 2001). This observation suggested that nucleotides other than ATP might be important for axonemal dynein function. However, to date, there is no experimental evidence to support this notion. Furthermore, these multi-heavy-chain motors also contain additional members of the LC8 and Tctex1 light-chain classes not found in cytoplasmic dynein, and also other lightchain components that allow the motors to sense and be regulated by external factors including redox poise, $\mathrm{Ca}^{2+}$ levels, and the mechanical state or local curvature experienced by the motors themselves. For example, the Chlamydomonas outer arm contains two bona fide thioredoxins, a calmodulin homolog and a leucine-rich repeat protein thought to be involved in sensing curvature that is actually the most highly conserved outer arm dynein-specific component.

\section{CYTOPLASMIC PREASSEMBLY AND TRAFFICKING OF DYNEIN ARM COMPLEXES}

Dynein heavy chains are massive proteins consisting of $\sim 4500$ residues. Consequently, their synthesis in the cytoplasm takes a considerable time; $>13$ min per molecule for a eukaryotic ribosome operating at a rate of 5.6 residues incorporated per sec (Ingolia et al. 2011) (BNID107952). During this time, there is clearly massive potential for protein aggregation because of exposure of hydrophobic core residues, and this is likely one reason why cells have evolved a complex series of cytoplasmic factors that are now known to be required for stable synthesis and maintenance of these proteins in cytoplasm before their transport into the ciliary compartment. These factors include LRRC50 (ODA7 in Chlamydomonas) (Duquesnoy et al. 2009), multiple PIH domain proteins (Omran et al. 2008; Yamamoto et al. 2010), and their interacting partners such as Dyxlc1 (Tarkar et al. 2013) that associate with Hsp70 and Hsp90 and are presumably playing a chaperone role in helping fold dynein components. Cur- rently, there is little information on the precise functional interplay among all of these molecules. Various dynein components are then specifically assembled to form discrete subcomplexes (such as that formed by the WD-repeat intermediate chains and a series of light chains) that are then associated with the heavy chains and regulatory light chains to yield complete dynein arm particles (Fowkes and Mitchell 1998). For the outer arm, recent studies show that the ODA5/ODA10 proteins are needed both in the cytoplasm to generate fully assembly-competent dynein particles and also in the axoneme in which, surprisingly, ODA10 assembles onto the proximal region of doublet \#1, which, in Chlamydomonas, is the only doublet that lacks outer dynein arms (Dean and Mitchell 2013). What role it plays there is uncertain at present. Inner arm dyneins appear to concentrate at the base of growing cilium where they can presumably be readily and rapidly injected through the ciliary gate at the transition zone into the ciliary compartment proper. Surprisingly, at least in Chlamydomonas, outer arm dyneins do not concentrate in this region but rather are found spread throughout the cytoplasmic volume, although why this should be remains unclear.

During growth of the cilium, the cell must transport axonemal dyneins from the cytoplasm into the ciliary shaft where they can then be assembled. There appear to be specific adaptors that are necessary to attach the different arms to the IFT machinery so they can be transported (Ahmed et al. 2008). However, once in the ciliary matrix, they must presumably be kept in an inactive state until fully assembled, otherwise they would likely interact with microtubule doublets and traffic toward the microtubule minus end at the ciliary base. One intriguing assembly factor (known as FBB18 in Chlamydomonas) appears to be present in the matrix (Austin-Tse et al. 2013) and could potentially be involved in keeping dyneins inactive until they have incorporated into the ciliary superstructure. As the various axonemal dyneins are present in different amounts and also differentially arranged along the axonemal length, the cell likely also has a sorting system 
that delivers these motors in the correct proportions and at the appropriate time during axoneme assembly. For example, motors only present in the distal region are presumably transported into the growing structure only during the latter phases of assembly. However, how this sorting might be achieved is completely unknown.

\section{ASSEMBLING DYNEIN ARMS IN THE AXONEMAL SUPERSTRUCTURE}

The basic axonemal building block is a $96-\mathrm{nm}$ repeat that contains four outer arms, one inner $\operatorname{arm~I1/f,~and~six~monomeric~inner~arms~in~}$ addition to two complete radial spokes and a third truncated spoke (Fig. 2). Also included in the repeat is the $\mathrm{N}$-DRC regulatory complex (Heuser et al. 2009) and the MIA complex (Yamamoto et al. 2013), which links the N-DRC to inner arm I1/f. Although the outer arms all appear to be identical in composition, one of the four in each repeat is physically connected through a linker structure to inner arm I1/f; it is this linker that is thought to provide a pathway for regulatory signals from the central pair/radial spokes to reach the outer arms. A key question in axoneme assembly is how this complex arrangement is patterned such that all the dynein arms are correctly located on the outer doublet microtubules. What is clear is that the mechanism(s) involved are robust as ectopic localization of dynein arms at inappropriate sites is never observed. In contrast, when purified dyneins are rebound to brain microtubules in vitro, they are capable of associating all around the microtubule circumference (Haimo and Fenton 1988). For the inner arm system, recent studies have revealed that a pair of extended coiled-coil proteins FAP59 and FAP172 (CCDC39 and CCDC40, in mammals) play a key role (Oda et al. 2014). These proteins asso-

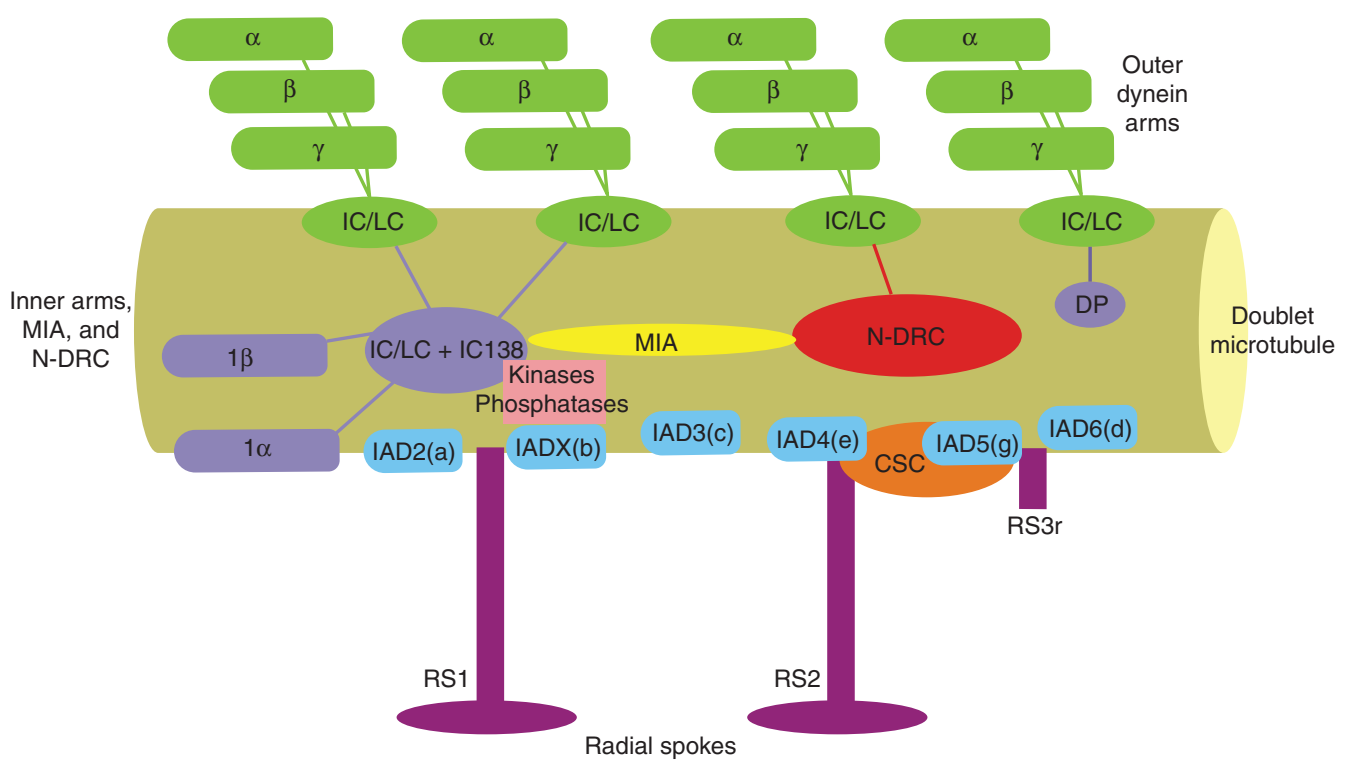

Figure 2. Arrangement of dyneins in the 96-nm axonemal repeat. Each axonemal repeat unit consists of four outer dynein arms arranged with a spacing of $24 \mathrm{~nm}$, a single inner arm I1/f, and six different monomeric heavychain inner arms. Linkages between the outer arms and other components vary on different microtubule doublets and also on the position along the axoneme. The N-DRC regulatory complex is linked to inner arm I1/f through the MIA complex, which provides a physical pathway for regulatory signals. Location of the radial spokes, the calmodulin and spoke-associated complex (CSC), and a distal projection that can interact with the last outer arm in the repeat are also shown. (From King 2013; reprinted, with permission, from the author under a Creative Commons License.) 
ciate together and span the repeat distance on the doublet microtubule surface. They provide defined docking sites for individual inner arms at specific locations along the repeat. For outer arms to interact with the doublet microtubules, an additional trimeric docking complex consisting of two coiled-coil proteins (DC1 and DC2) and a calmodulin homolog (DC3) is needed (Takada and Kamiya 1994). However, although this complex is necessary for outer arm association with the doublets, it does not appear sufficient to define the site of axonemal incorporation. Recently, an additional protein (CCDC103) has also been found to be necessary for outer arm insertion into the superstructure (Panizzi et al. 2012). This protein has rather remarkable biophysical properties including a very high $T_{m}$ and the ability to form dimers and higher order oligomers that are resistant to (or reform following) heating in the presence of SDS and reducing agents. In vitro, CCDC103 self-assembles into polymeric structures that can bind in linear arrays along the microtubule surface with a 12-nm periodicity (King and $\mathrm{Pa}$ tel-King 2015). Thus, one possibility is that CCDC103 polymers assemble during axonemal growth and provide a high-affinity track along the outer doublets with which the outer arms / docking complex can then associate.

\section{DYNEIN MOTOR FUNCTION AND REGULATION}

Both rows of dynein arms are capable of generating motive force (Paschal et al. 1987; Vale and Toyoshima 1988). When analyzed in vitro, individual dynein $\mathrm{HC}$ motors show discrete rates of microtubule translocation, different ATPase activities; and some (mainly the monomeric inner arms) also generate torque such that the gliding microtubules rotate as they move (Kagami and Kamiya 1992). Indeed, the outer arms increase cilia-generated propulsive force output by fourfold, and, in Chlamydomonas, beat frequency is reduced by approximately half in mutants unable to assemble outer arms (Kamiya and Okamoto 1985; Mitchell and Rosenbaum 1985). Furthermore, cilia retain the ability to essentially double their force output when placed under viscous load; this requires the outer arms (Yagi et al. 2005; Patel-King and King 2009). At least one mechanism involved in this response, is directed trafficking of the Lis1 regulatory factor into the ciliary matrix when load is encountered (Rompolas et al. 2012). For cytoplasmic dynein, Lis1 acts as a clutch to disengage the ATPase and microtubule-binding activities allowing this motor to drag large cargoes, such as nuclei, without releasing the microtubule (McKenney et al. 2010). In the cilium, Lis 1 has been found to associate with the $\alpha$ heavy chain within the outer arm and to increase the intrinsic beat frequency of reactivated cell models; that is, it enhances force output per unit time (Rompolas et al. 2012). In contrast, the inner arm system provides the exquisite control necessary to actually generate and propagate specific waveforms (Kamiya et al. 1991). Signals derived from the central pair/radial spokes and from the N-DRC are propagated directly through physical connections to the various inner arm dynein motors (Yamamoto et al. 2013). It is thought that this leads to dynein activation on individual doublets at appropriate intervals. The inner arm system is also controlled by the direct phosphorylation of the IC138 intermediate chain associated with inner arm I1/f. When phosphorylated by casein kinase 1 or protein kinase $\mathrm{A}$, this dynein shows slow microtubule gliding. However, dephosphorylation by PP1 and/or PP2A leads to faster sliding (Smith and Sale 1992; Alford et al. 2012). Ultimately, this regulatory pathway is controlled by signals emanating from the central pair microtubule complex.

To propagate a bend, dyneins along a given doublet must be sequentially activated so that a wave of motor activity transits the structure usually from base to tip. Current models based on direct physical activation of mutant cilia lacking particular axonemal structures propose that there are actually two distinct mechanosensory systems (Hayashibe et al. 1997). One involving the central pair and radial spokes that impacts the inner arms, and second distinct system that activates the outer arms. This second system is thought to involve the highly conserved leucine-rich repeat protein LC1 (Benash- 
Axonemal Dynein Arms

Table 1. Polypeptide composition of Chlamydomonas axonemal dyneins containing multiple heavy chains

\begin{tabular}{|c|c|c|c|}
\hline Dynein & Protein & $\begin{array}{l}\text { Mass } \\
(\mathrm{kDa})\end{array}$ & Description \\
\hline \multirow[t]{17}{*}{ Outer arm } & $\alpha \mathrm{HC}$ & 504 & $\begin{array}{l}\text { ATPase, microtubule motor; unusual amino-terminal domain consisting of } \\
\text { kelch repeats and immunoglobulin-like folds; not essential for outer arm } \\
\text { assembly; interacts with Lis1 to increase propulsive force output }\end{array}$ \\
\hline & $\beta \mathrm{HC}$ & 520 & $\begin{array}{l}\text { ATPase, microtubule motor; required for outer arm assembly; provides most } \\
\text { of the power output }\end{array}$ \\
\hline & $\gamma \mathrm{HC}$ & 513 & $\begin{array}{l}\text { ATPase, microtubule motor; required for outer arm assembly; appears to be } \\
\text { the key regulatory node integrating multiple signaling inputs }\end{array}$ \\
\hline & IC1 & 76 & $\begin{array}{l}\text { WD-repeat protein, binds microtubules in an ATP-independent manner; } \\
\text { required for outer arm assembly }\end{array}$ \\
\hline & IC2 & 63 & WD-repeat protein; required for outer arm assembly \\
\hline & Lis1 & 37 & $\begin{array}{l}\text { Entry into cilium is regulated in response to perceived load; binds the } \alpha \mathrm{HC} \\
\text { to increase propulsive force output }\end{array}$ \\
\hline & $\mathrm{LC} 1$ & 22 & $\begin{array}{l}\text { Leucine-rich repeat protein; one copy binds to the microtubule-binding } \\
\text { domain of the } \gamma \mathrm{HC} \text {; also binds microtubules directly; proposed to act as a } \\
\text { sensor of axonemal curvature }\end{array}$ \\
\hline & LC2 & 16 & Tctex2; binds the ICs and LC6 \\
\hline & LC3 & 17 & Thioredoxin associated with amino-terminal region of $\beta \mathrm{HC}$ \\
\hline & $\mathrm{LC} 4$ & 18 & $\begin{array}{l}\text { Calmodulin homolog; specifically binds } \mathrm{Ca}^{2+} \text { and controls structural } \\
\text { rigidity of } \gamma \mathrm{HC} \text { amino-terminal region }\end{array}$ \\
\hline & LC5 & 14 & Thioredoxin associated with amino-terminal region of $\alpha \mathrm{HC}$ \\
\hline & LC6 & 14 & Chlamydomonas-specific variant of LC8 \\
\hline & LC7a & 12 & Related to mammalian roadblock/DYNLRB; associates with ICs \\
\hline & LC7b & 11 & $\begin{array}{l}\text { Related to mammalian roadblock/DYNLRB; associates with ICs and } \\
\text { interacts with docking complex and LC3 }\end{array}$ \\
\hline & LC8 & 10 & $\begin{array}{l}\text { Extraordinarily highly conserved; acts as a dimerization hub and is found in } \\
\text { a large number of macromolecular complexes; interacts with ICs }\end{array}$ \\
\hline & LC9 & 13 & Dimeric Tctex1 homolog; associates with ICs \\
\hline & LC10 & 12 & $\begin{array}{l}\text { LC8 variant; apparently outer arm specific; in mammals, the ortholog } \\
\text { (DNAL4) is very highly expressed suggesting additional roles }\end{array}$ \\
\hline \multirow{11}{*}{$\begin{array}{l}\text { Inner arm } \\
\quad \mathrm{I} 1 / \mathrm{f}\end{array}$} & $1 \alpha \mathrm{HC}$ & 523 & ATPase, microtubule motor; required for inner arm assembly \\
\hline & $1 \beta \mathrm{HC}$ & 510 & ATPase, microtubule motor; required for inner arm assembly \\
\hline & IC140 & 110 & WD-repeat protein; required for inner arm assembly \\
\hline & IC138 & 111 & $\begin{array}{l}\text { WD-repeat protein; phosphorylated by casein kinase } 1 \text { and protein kinase A; } \\
\text { regulates motor activity }\end{array}$ \\
\hline & IC97 & 90 & $\begin{array}{l}\text { Ortholog of mammalian LAS } 1 \text { that is implicated in lung tumor formation; } \\
\text { interacts with tubulin and IC140/IC138 }\end{array}$ \\
\hline & FAP120 & 32 & Contains ankyrin repeats \\
\hline & Tctex 1 & 12 & Dimer, associates with ICs; LC9 homolog \\
\hline & Tctex $2 b$ & 14 & Related to LC2 \\
\hline & LC7a & 12 & $\begin{array}{l}\text { Related to mammalian roadblock/DYNLRB; associates with ICs; also } \\
\text { present in outer arm dynein }\end{array}$ \\
\hline & LC7b & 11 & $\begin{array}{l}\text { Related to mammalian roadblock/DYNLRB; associates with ICs; also } \\
\text { present in outer arm dynein }\end{array}$ \\
\hline & LC8 & 10 & $\begin{array}{l}\text { Extraordinarily highly conserved; acts as a dimerization hub and is found in } \\
\text { a large number of macromolecular complexes; interacts with ICs; also } \\
\text { present in outer arm dynein }\end{array}$ \\
\hline
\end{tabular}


ski et al. 1999; Wu et al. 2000) that has recently been shown to bind the microtubule-binding domain of the $\gamma$ heavy chain (Ichikawa et al. 2015). When mutant forms of this protein are expressed in a wild-type background, they yield dominant negative effects that have dramatic consequences on swimming velocity and on the ability of the cilia to maintain hydrodynamic coupling (Patel-King and King 2009; Rompolas et al. 2010).

Many organisms are able to change their ciliary beat pattern in response to specific signals. In Chlamydomonas, switching between forward motion using an asymmetric or ciliary beat and backward movement driven by a symmetric sinusoidal waveform is mediated by altering intraciliary $\mathrm{Ca}^{2+}$ (Bessen et al. 1980). This switch from forward to backward motion occurs in two steps: first the cilia stop beating as $\mathrm{Ca}^{2+}$ increases to $\sim 10^{-5} \mathrm{M}$ and then they restart with the different waveform as levels increase further. It is this latter step that requires the outer dynein arms as mutant cilia lacking these structures either just stop beating or show a highly aberrant waveform transition at high $\mathrm{Ca}^{2+}$. This suggests that there may be two $\mathrm{Ca}^{2+}$ sensors necessary to mediate the complete response. The most likely candidate for the outer arm $\mathrm{Ca}^{2+}$ sensor that leads to waveform conversion is LC4, which is an EF-hand protein shown to specifically interact with $\mathrm{Ca}^{2+}$ (King and Patel-King 1995a). This protein binds to two distinct segments of the $\gamma$ heavy-chain amino-terminal region and, in the absence of $\mathrm{Ca}^{2+}$, acts as a rigid strut maintaining a bent orientation in this heavy-chain domain (Sakato et al. 2007). However, when $\mathrm{Ca}^{2+}$ increases, LC4 appears to detach from one site on the heavy-chain amino-terminal region and instead interacts directly with IC1. This allows the $\gamma$ heavy-chain amino-terminal domain to adopt conformations not attainable in the absence of the ligand. How this structural change might then manifest itself as an alteration in waveform is still not clear. The other known Chlamydomonas outer arm $\mathrm{Ca}^{2+}$-binding protein is the docking complex DC3 component (Casey et al. 2003a). However, this protein can bind both $\mathrm{Ca}^{2+}$ and $\mathrm{Mg}^{2+}$ and its absence does not abrogate waveform conversion (Casey et al. 2003b). There is also the possibility that soluble calmodulin present in the ciliary matrix transiently interacts with the two IQ motifs located on the $\gamma$ heavy-chain amino-terminal region as $\mathrm{Ca}^{2+}$ increases.

Outer arm dyneins also contain thioredoxins either as individual light chains (as in Chlamydomonas) or as part of a modular intermediate chain (metazoans) that also has functional nucleoside diphosphate kinase catalytic cores (Ogawa et al. 1996; Patel-King et al. 1996; Padma et al. 2001). These thioredoxin units are redox-active, and it was subsequently found that beat frequency can be controlled by alterations in cellular redox state (Wakabayashi and King 2006). This response appears to be mediated through the formation of different mixed disulfides in vivo. Furthermore, in vitro experiments revealed that changes in the redox state of these dynein-associated thioredoxin moieties also affected motility. Indeed, the beat frequency of reactivated cell models can be controlled simply by manipulating the GSH:GSSG ratio in glutathione redox buffers. In Chlamydomonas, both the $\alpha$ and $\beta$ heavy chains have associated thioredoxins (LC5 and LC3, respectively), and it was found that lack of the $\alpha$ heavy chain and LC5 resulted in cell models that could not respond to redox changes presumably caused by disruption of an intradynein redox cascade (Wakabayashi and King 2006).

\section{CONSEQUENCES OF DYNEIN ARM DYSFUNCTION}

In Chlamydomonas, lack of outer dynein arms results in a drop in ciliary beat frequency to approximately half that of wild-type, whereas lack of inner arms alters the normal waveform by decreasing the angular size of the principal bend. However, apart from slow motility, there appear to be no other consequences for these unicellular organisms, at least in the laboratory. In contrast, in vertebrates (including humans), ciliary motility and the consequent fluid flow powered by axonemal dyneins, play key roles in development, reproduction, and organismal homeostasis (Fliegauf et al. 2007; Becker-Heck 
et al. 2012). Reduction of ciliary beat frequency caused by mutations within axonemal dyneins or their cytoplasmic assembly factors leads to primary ciliary dyskinesia (PCD), which includes multiple phenotypes of varying severity depending on the precise mutational target (Becker-Heck et al. 2012). In general, patients with PCD show highly reduced fertility because of poor sperm motility in males and reduction in beat frequency of the cilia lining the fallopian tubes in females that are involved in oocyte movement toward the uterus. Dysfunctional cilia also result in sometimes-severe bronchial problems caused by the inability of the lungs to clear secreted mucus, which acts to protect the tissue from inhaled pollutants and pathogens. Cilia also line the brain ventricles and in many vertebrates ependymal ciliary dysfunction leads to hydrocephalus. One other major consequence of ciliary immotility is that $\sim 50 \%$ of patients with PCD will show "situs inversus," in which the position of the internal organs is reversed. Several forms are known including partial reversals within either the abdominal or thoracic cavities. This is caused during embryogenesis as ciliary beating at the embryonic node is required to set up left-right asymmetry. In the absence of ciliary motility, the embryo breaks symmetry randomly resulting in a 50\% chance of incorrect "situs." In general, patients with "situs inversus totalis" are asymptomatic. However, in some cases, the embryo fails to setup a left-right axis and this leads to heterotaxy and severe heart deformations, which can require surgical intervention for survival. Also of note is that defects in the dynein that power retrograde IFT also have severe phenotypic consequences. In humans, dysfunction of this motor complex results in developmental problems including severe (often fatal) skeletal abnormalities such as those observed for Jeune's asphyxiating thoracic dystrophy and short-rib polydactyly (Schmidts et al. 2013).

\section{CONCLUDING REMARKS}

Axonemal dyneins represent a highly divergent and complex class of motors whose ensemble activity results in exquisitely controlled ciliary beating. Although much has been learned about these motors in terms of their composition, location, and in vitro properties, there remain many outstanding questions concerning how they are assembled in cytoplasm, specifically trafficked into the cilium, and then located at precise sites within the axonemal superstructure. Furthermore, even though high-resolution structures are now available for dynein motor domains there is still much to be understood about the precise arrangement and function of the many other components that comprise these motors.

\section{ACKNOWLEDGMENTS}

S.M.K.'s laboratory is supported by Grant GM051293 from the National Institutes of Health (NIH).

\section{REFERENCES}

Ahmed N, Gao C, Lucker B, Cole D, Mitchell D. 2008. ODA16 aids axonemal outer row dynein assembly through an interaction with the intraflagellar transport machinery. J Cell Biol 183: 313-322.

Alford L, Wirschell M, Yamamoto R, Sale WS. 2012. Control of axonemal inner dynein arms. In Dyneins: Structure, biology and disease (ed. King SM), pp. 313-335. Elsevier, Waltham, MA.

Austin-Tse C, Halbritter J, Zariwala MA, Gilberti ReM, Gee HY, Hellman N, Pathak N, Liu Y, Panizzi JR, Patel-King RS, et al. 2013. Zebrafish ciliopathy screen plus human mutational analysis identifies C21orf59 and CCDC65 defects as causing primary ciliary fyskinesia. Am J Hum Genet 93: 672-686.

Becker-Heck A, Loges NT, Omran H. 2012. Dynein dysfunction as a cause of primary ciliary dyskinesia and other ciliopathies. In Dyneins: Structure, biology and disease (ed. King SM), pp. 603-627. Elsevier, Waltham, MA.

Benashski SE, Patel-King RS, King SM. 1999. Light chain 1 from the Chlamydomonas outer dynein arm is a leucinerich repeat protein associated with the motor domain of the $\gamma$ heavy chain. Biochemistry 38: 7253-7264.

Bessen M, Fay RB, Witman GB. 1980. Calcium control of waveform in isolated flagellar axonemes of Chlamydomonas. J Cell Biol 86: 446-455.

Bowman AB, Patel-King RS, Benashski SE, McCaffery JM, Goldstein LS, King SM. 1999. Drosophila roadblock and Chlamydomonas LC7: A conserved family of dynein-associated proteins involved in axonal transport, flagellar motility, and mitosis. J Cell Biol 146: 165-180.

Casey D, Inaba K, Pazour G, Takada S, Wakabayashi K, Wilkerson C, Kamiya R, Witman G. 2003a. DC3, the 21-kD subunit of the outer dynein arm-docking complex (ODA-DC), is a novel EF-hand protein important for 
S.M. King

assembly of both the outer arm and the ODA-DC. Mol Biol Cell 14: 3650-3663.

Casey D, Yagi T, Kamiya R, Witman G. 2003b. DC3, the smallest subunit of the Chlamydomonas flagellar outer dynein arm-docking complex, is a redox-sensitive calcium-binding protein. J Biol Chem 278: 42652-42659.

Dean AB, Mitchell DR. 2013. Chlamydomonas ODA10 is a conserved axonemal protein that plays a unique role in outer dynein arm assembly. Mol Biol Cell 24: 3689-3696.

Duquesnoy P, Escudier E, Vincensini L, Freshour J, Bridoux AM, Coste A, Deschildre A, de Blic J, Legendre M, Montantin G, et al. 2009. Loss-of-function mutations in the human ortholog of Chlamydomonas reinhardtii ODA7 disrupt dynein arm assembly and cause primary ciliary dyskinesia. Am J Hum Genet 85: 890-896.

Fliegauf M, Benzing T, Omran H. 2007. When cilia go bad: Cilia defects and ciliopathies. Nat Rev Mol Cell Biol 8: 880-893.

Fowkes ME, Mitchell DR. 1998. The role of preassembled cytoplasmic complexes in assembly of flagellar dynein subunits. Mol Biol Cell 9: 2337-2347.

Haimo LT, Fenton RD. 1988. Interaction of Chlamydomonas dynein with tubulin. Cell Motil Cytoskeleton 9: 129-139.

Harrison A, Olds-Clarke P, King SM. 1998. Identification of the $t$ complex-encoded cytoplasmic dynein light chain Tctex1 in inner arm I1 supports the involvement of flagellar dyneins in meiotic drive. J Cell Biol 140: 11371147.

Hayashibe K, Shingyoji C, Kamiya R. 1997. Induction of temporary beating in paralyzed flagella of Chlamydomonas mutants by application of external force. Cell Motil Cytoskeleton 37: 232-239.

Heuser T, Raytchev M, Krell J, Porter ME, Nicastro D. 2009. The dynein regulatory complex is the nexin link and a major regulatory node in cilia and flagella. J Cell Biol 187: 921-933.

Hom E, Witman GB, Harris EH, Dutcher SK, Kamiya R, Mitchell DR, Pazour GJ, Porter ME, Sale WS, Wirschell M, et al. 2011. A unified taxonomy for ciliary dyneins. Cytoskeleton 68: 555-565.

Ichikawa M, Saito K, Yanagisawa HA, Yagi T, Kamiya R, Yamaguchi S, Yajima J, Kushida Y, Nakano K, Numata O, et al. 2015. Axonemal dynein light chain-1 locates at the microtubule-binding domain of the $\gamma$ heavy chain. Mol Biol Cell 26 4236-4247.

Ingolia N, Lareau L, Weissman J. 2011. Ribosome profiling of mouse embryonic stem cells reveals the complexity and dynamics of mammalian proteomes. Cell 147: 789-802.

Kagami O, Kamiya R. 1992. Translocation and rotation of microtubules caused by multiple species of Chlamydomonas inner-arm dynein. J Cell Sci 103: 653-664.

Kamiya R, Okamoto M. 1985. A mutant of Chlamydomonas reinhardtii that lacks the flagellar outer dynein arm but can swim. J Cell Sci 74: 181-191.

Kamiya R, Kurimoto E, Muto E. 1991. Two types of Chlamydomonas flagellar mutants missing different components of inner-arm dynein. J Cell Biol 112: 441-447.

Kato-Minoura T, Hirono M, Kamiya R. 1997. Chlamydomonas inner-arm dynein mutant, ida5, has a mutation in an actin-encoding gene. J Cell Biol 137: 649-656.
Kato-Minoura T, Uryu S, Hirono M, Kamiya R. 1998. Highly divergent actin expressed in a Chlamydomonas mutant lacking the conventional actin gene. Biochem Biophys Res Commun 251: 71-76.

King SM. 2010. Axonemal dyneins winch the cilium. Nat Struct Mol Biol 17: 673-674.

King SM. 2012a. Composition and assembly of axonemal dyneins. In Dyneins: Structure, biology and disease (ed. King SM), pp. 209-243. Elsevier, Waltham, MA.

King SM. 2012b. Integrated control of axonemal dynein $\mathrm{AAA}^{+}$motors. J Struct Biol 179: 222-228.

King SM. 2013. A solid-state control system for dyneinbased ciliary/flagellar motility. J Cell Biol 201: 173-175.

King SM, Patel-King RS. 1995a. Identification of a $\mathrm{Ca}^{2+}$ binding light chain within Chlamydomonas outer arm dynein. J Cell Sci 108: 3757-3764.

King SM, Patel-King RS. 1995b. The $M_{r}=8,000$ and 11,000 outer arm dynein light chains from Chlamydomonas flagella have cytoplasmic homologues. J Biol Chem 270: 11445-11452.

King SM, Patel-King RS. 2015. The oliogmeric outer arm dynein assembly factor CCDC103 is tightly integrated within the ciliary axoneme and exhibits periodic binding to microtubules. J Biol Chem 290: 7388-7401.

LeDizet M, Piperno G. 1995. ida4-1, ida4-2, and ida4-3 are intron splicing mutations affecting the locus encoding p28, a light chain of Chlamydomonas axonemal inner dynein arms. Mol Biol Cell 6: 713-723.

McKenney RJ, Vershinin M, Kunwar A, Vallee RB, Gross SP. 2010. LIS1 and NudE induce a persistent dynein forceproducing state. Cell 141: 304-314.

Mitchell DR, Kang Y. 1991. Identification of oda6 as a Chlamydomonas dynein mutant by rescue with the wild-type gene. J Cell Biol 113: 835-842.

Mitchell DR, Rosenbaum JL. 1985. A motile Chlamydomonas flagellar mutant that lacks outer dynein arms. J Cell Biol 100: $1228-1234$.

Oda T, Yanagisawa H, Kamiya R, Kikkawa M. 2014. A molecular ruler determines the repeat length in eukaryotic cilia and flagella. Science 346: 857-860.

Ogawa K, Takai H, Ogiwara A, Yokota E, Shimizu T, Inaba K, Mohri H. 1996. Is outer arm dynein intermediate chain 1 multifunctional? Mol Biol Cell 7: 1895-1907.

Omran H, Kobayashi D, Olbrich H, Tsukahara T, Loges NT, Hagiwara H, Zhang Q, Leblond G, O'Toole E, Hara C, et al. 2008. Ktu/PF13 is required for cytoplasmic preassembly of axonemal dyneins. Nature 456: 611-616.

Padma P, Hozumi A, Ogawa K, Inaba K. 2001. Molecular cloning and characterization of a thioredoxin/nucleoside diphosphate kinase related dynein intermediate chain from the ascidian, Ciona intestinalis. Gene 275: 177-183.

Panizzi J, Becker-Heck A, Castleman V, Al-Mutairi D, Liu Y, Loges NT, Pathak N, Austin-Tse C, Sheridan E, Schmidts $\mathrm{M}$, et al. 2012. CCDC103 mutations cause primary ciliary dyskinesia by disrupting assembly of ciliary dynein arms. Nat Genet 44: 714-719.

Paschal BM, King SM, Moss AG, Collins CA, Vallee RB, Witman GB. 1987. Isolated flagellar outer arm dynein translocates brain microtubules in vitro. Nature 330: $672-674$. 
Patel-King RS, King SM. 2009. An outer arm dynein light chain acts in a conformational switch for flagellar motility. J Cell Biol 186: 283-295.

Patel-King RS, Benashki SE, Harrison A, King SM. 1996. Two functional thioredoxins containing redox-sensitive vicinal dithiols from the Chlamydomonas outer dynein arm. J Biol Chem 271: 6283-6291.

Rompolas P, Patel-King RS, King SM. 2010. An outer arm dynein conformational switch is required for metachronal synchrony of motile cilia in planaria. Mol Biol Cell 21: 3669-3679.

Rompolas P, Patel-King RS, King SM. 2012. Association of Lis1 with outer arm dynein is modulated in response to alterations in flagellar motility. Mol Biol Cell 23: $3554-$ 3656.

Sakato M, Sakakibara H, King SM. 2007. Chlamydomonas outer arm dynein alters conformation in response to $\mathrm{Ca}^{2+}$. Mol Biol Cell 18: 3620-3634.

Schmidts M, Arts HH, Bongers EMHF, Yap A, Oud MM, Antony D, Duijkers L, Emes RD, Stalker J, Yntema JBL, et al. 2013. Exome sequencing identifies DYNC2H1 mutations as a common cause of asphyxiating thoracic dystrophy (Jeune syndrome) without major polydactyly, renal or retinal involvement. J Med Genet 50: 309-323.

Smith EF, Sale WS. 1992. Regulation of dynein-driven microtubule sliding by the radial spokes in flagella. Science 257: $1557-1559$.

Takada S, Kamiya R. 1994. Functional reconstitution of Chlamydomonas outer dynein arms from $\alpha-\beta$ and $\gamma$ subunits: Requirement of a third factor. J Cell Biol 126: 737-745.

Tarkar A, Loges NT, Slagle CE, Francis R, Dougherty GW, Tamayo JV, Shook B, Cantino M, Schwartz D, Jahnke C, et al. 2013. DYX1C1 is required for axonemal dynein assembly and ciliary motility. Nat Genet 45: 995-1003.

Vale RD, Toyoshima YY. 1988. Rotation and translocation of microtubules in vitro induced by dyneins from Tetrahymena cilia. Cell 52: 459-469.

Wakabayashi K, King SM. 2006. Modulation of Chlamydomonas reinhardtii flagellar motility by redox poise. J Cell Biol 173: 743-754.

Wilkerson CG, King SM, Koutoulis A, Pazour GJ, Witman GB. 1995. The 78,000 $M_{r}$ intermediate chain of Chlamydomonas outer arm dynein is a WD-repeat protein required for arm assembly. J Cell Biol 129: 169-178.

Wu H, Maciejewski MW, Marintchev A, Benashski SE, Mullen GP, King SM. 2000. Solution structure of a dynein motor domain associated light chain. Nat Struct Biol 7: 575-579.

Yagi T, Minoura I, Fujiwara A, Saito R, Yasunaga T, Hirono M, Kamiya R. 2005. An axonemal dynein particularly important for flagellar movement at high viscosity: Implications from a new Chlamydomonas mutant deficient in the dynein heavy chain gene DHC9. J Biol Chem 280: $41412-41420$.

Yagi T, Uematsu K, Liu Z, Kamiya R. 2009. Identification of dyneins that localize exclusively to the proximal portion of Chlamydomonas flagella. J Cell Sci 122: 1306-1314.

Yamamoto R, Hirono M, Kamiya R. 2010. Discrete PIH proteins function in the cytoplasmic preassembly of different subsets of axonemal dyneins. J Cell Biol 190: 65-71.

Yamamoto R, Song K, Yanagisawa H, Fox L, Yagi T, Wirschell M, Hirono M, Kamiya R, Nicastro S, Sale WS. 2013. The MIA complex is a conserved and novel dynein regulator essential for normal ciliary motility. J Cell Biol 201: 263-278. 


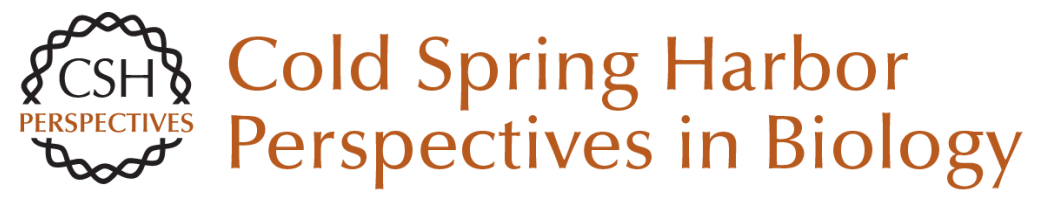

\section{Axonemal Dynein Arms}

Stephen M. King

Cold Spring Harb Perspect Biol 2016; doi: 10.1101/cshperspect.a028100 originally published online August 15, 2016

\section{Subject Collection Cilia}

Ciliary Mechanisms of Cyst Formation in Polycystic Kidney Disease

Ming Ma, Anna-Rachel Gallagher and Stefan Somlo

Photoreceptor Cilia and Retinal Ciliopathies Kinga M. Bujakowska, Qin Liu and Eric A. Pierce

G-Protein-Coupled Receptor Signaling in Cilia Kirk Mykytyn and Candice Askwith

Evolution of Cilia David R. Mitchell

Transition Zone Migration: A Mechanism for Cytoplasmic Ciliogenesis and Postaxonemal Centriole Elongation

Tomer Avidor-Reiss, Andrew Ha and Marcus L. Basiri

Cilia and Obesity

Christian Vaisse, Jeremy F. Reiter and Nicolas F. Berbari

Posttranslational Modifications of Tubulin and Cilia

Dorota Wloga, Ewa Joachimiak, Panagiota Louka, et al.
Cilia in Left-Right Symmetry Breaking Kyosuke Shinohara and Hiroshi Hamada

Discovery, Diagnosis, and Etiology of Craniofacial Ciliopathies Elizabeth N. Schock and Samantha A. Brugmann

Axoneme Structure from Motile Cilia Takashi Ishikawa

Cilia and Ciliopathies in Congenital Heart Disease Nikolai T. Klena, Brian C. Gibbs and Cecilia W. Lo

Sperm Sensory Signaling Dagmar Wachten, Jan F. Jikeli and U. Benjamin Kaupp

Primary Cilia and Coordination of Receptor Tyrosine Kinase (RTK) and Transforming Growth Factor $\beta$ (TGF- $\beta$ ) Signaling Søren T. Christensen, Stine K. Morthorst, Johanne B. Mogensen, et al.

Primary Cilia and Mammalian Hedgehog Signaling Fiona Bangs and Kathryn V. Anderson

For additional articles in this collection, see http://cshperspectives.cshlp.org/cgi/collection/

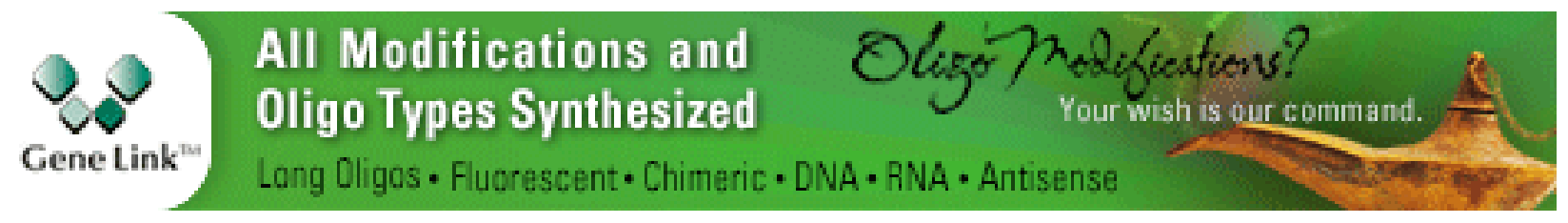

Copyright @ 2016 Cold Spring Harbor Laboratory Press; all rights reserved 
Radial Spokes--A Snapshot of the Motility Regulation, Assembly, and Evolution of Cilia and Flagella

Xiaoyan Zhu, Yi Liu and Pinfen Yang
Cilia and Mucociliary Clearance

Ximena M. Bustamante-Marin and Lawrence E. Ostrowski

For additional articles in this collection, see http://cshperspectives.cshlp.org/cgi/collection/

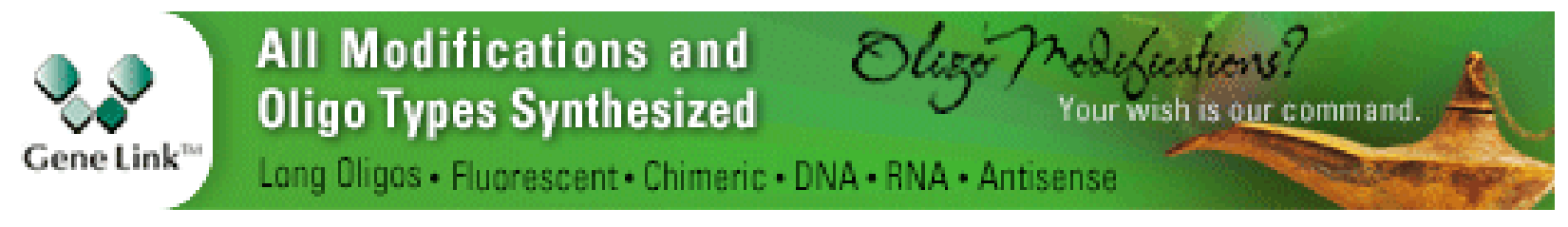

Copyright @ 2016 Cold Spring Harbor Laboratory Press; all rights reserved 